\title{
Examination of the Effect of Aphid Vector Population Composition on the Spatial Dynamics of Citrus Tristeza Virus Spread by Stochastic Modeling
}

\author{
T. R. Gottwald, G. J. Gibson, S. M. Garnsey, and M. Irey
}

First and third authors: USDA, Agricultural Research Service, Orlando, FL 32803; second author: Biomathematics and Statistics Scotland, Edinburgh, United Kingdom; and fourth author: U.S. Sugar Corporation, Clewiston, FL.

Accepted for publication 21 April 1999.

\begin{abstract}
Gottwald, T. R., Gibson, G. J., Garnsey, S. M., and Irey, M. 1999. Examination of the effect of aphid vector population composition on the spatial dynamics of citrus tristeza virus spread by stochastic modeling. Phytopathology 89:603-608.

Aphid vector species population composition is known to affect the spatial patterns of citrus tristeza virus (CTV) and the changes in these patterns over time. However, the biological processes that are associated with virus spread have not been well defined. The spatiotemporal dynamics of CTV were examined using data collected from research plots in the Dominican Republic and Costa Rica, where the brown citrus aphid (BCA), Toxoptera citricida, was the predominant species, and in Florida, where the BCA was absent and the melon aphid, Aphis gossypii, was the predom-

inant vector. Data were analyzed using a spatiotemporal stochastic model for disease spread, and parameter values were evaluated using Markov chain Monte Carlo stochastic integration methods. Where the melon aphid was the dominant species, the model parameter likelihood values supported the hypothesis that the disease was spread through a combination of random background transmission (transmission originating from inoculum sources outside the plot) and a local interaction (transmission from inoculum sources within the plot) operating over short distances. Conversely, when BCA was present, results often suggested a local shortrange transmission interaction that was not restricted to nearest-neighbor interactions and that the presence of background infection was not necessary to explain the observations.
\end{abstract}

The most important virus of citrus in the United States and worldwide is the citrus tristeza closterovirus (CTV), which causes several distinct diseases $(1,24)$. An important problem affecting U.S. citrus production is a CTV-induced decline of trees on sour orange rootstocks associated with a virus-induced budunion incompatibility (25). Over 50 million trees worldwide have been killed by CTV decline. The use of sour orange has decreased in recent years; however, nearly all citrus in Texas, 15 to $20 \%$ of the trees in Florida and California, and nearly $100 \%$ of the trees in Italy and Mexico are still on sour orange. Production and tree losses due to CTV exceeding $\$ 500$ million over the next 20 years have been projected for Florida alone (Florida BrCA/CTV Action Plan). CTV-induced decline can be avoided by using decline-tolerant rootstocks, but these often have other drawbacks (5). Use of decline-tolerant rootstocks also does not solve the second major disease problem caused by CTV, which is a stem-pitting reaction in scion cultivars that reduces tree vigor and fruit yield and quality (24). CTV isolates that cause severe stem pitting are not yet common in the United States but are prevalent in most foreign citrus production areas and represent the major future threat of CTV to the U.S. citrus industry $(1,12,24)$. CTV stem pitting affects the scion irrespective of the rootstock, and the genes regulating stem pitting and decline are independent (11). Stem pitting is especially severe in lime and grape-

Corresponding author: T. R. Gottwald; E-mail address: t.r.gott@ worldnet.att.net

Mention of a trademark, warranty, proprietary product, or vendor does not constitute a guarantee by the U.S. Department of Agriculture and does not imply its approval to the exclusion of other products or vendors that may also be suitable.

Publication no. P-1999-0521-02R

This article is in the public domain and not copyrightable. It may be freely reprinted with customary crediting of the source. The American Phytopathological Society, 1999. fruit, but may also affect sweet orange. Mandarin is tolerant and trifoliate orange and some trifoliate hybrids are resistant to infection (10).

Four aphid species have been demonstrated to transmit CTV: Aphis gossypii Glover, the cotton or melon aphid; A. spiraecola Patch, the spirea aphid; Toxoptera aurantii (Boyer de Fonscolombe), the black citrus aphid; and T. citricida (Kirkaldy), the brown citrus aphid (BCA). Of these, $T$. citricida is considered the most efficient vector $(2,3,7,17,26,27)$. Yokomi et al. $(27,28)$ demonstrated that $T$. citricida is up to 25 times more efficient at transmitting some CTV isolates than is the next most efficient vector species, A. gossypii. Where T. citricida is absent, such as in California, Spain, and Israel, A. gossypii is apparently the primary vector of CTV. Citrus is the primary host for $T$. citricida, which can form large colonies on the host under favorable conditions $(3,26,28)$. In contrast, citrus is not a primary host for $A$. gossypii, which does not heavily colonize this host. Apparently, CTV is vectored by A. gossypii as migrants of this aphid species more through the orchards from surrounding areas or crops. Over the last 10 years, T. citricida has spread northward from South America into most islands in the Caribbean and into Central America $(7,8,19,28)$. It was discovered in southeast Florida in 1995 and has since spread into all major citrus areas of the state (28). The transmission efficiency of $T$. citricida, combined with the large populations it establishes in commercial citrus in relationship to native aphid species, has generated considerable concern by both citrus producers and regulatory agencies throughout the United States as well as other nations of the Caribbean and Central America. This is, in part, due to reports that the spatial and temporal dynamics of CTV appear to change as $T$. citricida becomes part of the pathosystem, which results in elevated CTV incidence, spread, and CTV-related tree and crop losses $(17,24,28)$. Thus, one way to examine and contrast the CTV pathosystems is by the predominant CTV vector, i.e., A. gossypii versus T. citricida, present during the duration of an epidemic (18). 
Previous temporal and spatiotemporal studies of CTV have almost exclusively involved the A. gossypii pathosystem $(6,9,16,21$, 22). Spatial analyses of patterns of CTV-infected trees in Israel indicated some aggregated patterns in contrast to recent analyses of studies in Spain that yielded little evidence against the hypothesis that they were random $(16,18,21)$. However, using a spatiotemporal stochastic model, fitted using Markov chain Monte Carlo (MCMC) methods, Gibson and Austin (15) elicited evidence that the A. gossypii pathosystem exhibited aggregation of virus infection consistent with a so-called local transmission mechanism, that is, when the locations of new infections depend on the locations of previously infected plants. Subsequent work with an expanded model elicited evidence that new infections were governed by a combination of background (new infections from inoculum outside the plot) and local transmission (13). In contrast, the dynamics of the T. citricida pathosystem appear to be somewhat different. Using a combination of four spatial analysis methods, recent studies of CTV epidemics in the presence of T. citricida suggested that CTV spread was predominantly to trees within a local area. The authors did not detect patterns of longer distance spread within the confines of the plot sizes tested but were able to demonstrate that CTV is often aggregated at several special hierarchies when $T$. citricida is the primary vector $(16-18,20)$.

In Gibson's (13) spatiotemporal analysis, he considered two Spanish CTV data sets. However, these included only three assessments over time and only when A. gossypii was the presumed predominant CTV vector species. In the current study, we apply this same methodology to examine multiple assessments over time to compare the pathosystems characterized by predominance of either $A$. gossypii or T. citricida vectors. The purpose of this study was to examine the spatial patterns of CTV and relate these to the possible underlying mechanisms that affect CTV spread in relationship to the two aforementioned pathosystems. Specifically, the considerations were the contribution and range of local transmission (i.e., acquisition of the virus from CTV-positive individuals in the host lattice followed by transmission to other individuals within the lattice) and the contribution of background transmission (i.e., virus transmission from vectors originating outside the host population being studied).

\section{MATERIALS AND METHODS}

Experimental design. The research plots studied are presented in two major categories, separated by the predominant aphid vector species present in the plots.

I. Plot design in which A. gossypii was the predominant vector species $=\mathrm{A}$. gossypii/CTV pathosystem. In this category, data were collected annually over a 7-year period from 1989 to 1995 in nine plots established within large commercial plantings of the U.S. Sugar Corporation in south Florida. All plots consisted of Rhode Red Valencia orange, Citrus sinensis (L.) Osbeck, grafted on sour orange, C. aurantium L., rootstock planted in 1987. Each plot consisted of approximately 476 trees arranged in 14 north-south-oriented rows of trees, each with 34 trees per row in a rectangular pattern. All data were collected prior to the 1996 introduction of $T$. citricida into Florida. Virus incidence was low $(<5 \%)$ for all plots at the beginning of the study.

II. Plot design in which T. citricida was the predominant vector species $=\mathrm{T}$. citricida/CTV pathosystem . In this category, data were collected from eight plots, each established within commercial plantations, four in northwest Costa Rica and four in south central Dominican Republic. All plots within this category consisted of 20 rows of trees, each with 20 trees per row. Of these, seven plots were composed of orange scion varieties and one was grapefruit. All plots consisted of approximately 20 rows of trees, each with 20 trees per row in a rectangular planting pattern within larger commercial plantings, and plantings ranged from 1 to 5 years old at the beginning of the study. The Costa Rica plots were desig- nated CR1 = a pineapple sweet orange planting on Cleopatra mandarin rootstock, located near Los Inocentes; CR2 = a Valencia sweet orange planting on Cleopatra mandarin, $C$. reticulata Blanco, rootstock, located near Birmania; CR3 = a Valencia sweet orange planting on local grapefruit, $C$. paradisi Macf., rootstock, located near Brazilia; and CR4 = a pineapple sweet orange planting on carrizo, Poncirus trifoliata (L.) Raf. $\times$ C. sinensis, rootstock, located near Los Inocentes. The Dominican Republic plots were designated DR $1=$ a Valencia sweet orange planting on carrizo rootstock, located near La Lecheria; DR2 = a Valencia sweet orange planting on carrizo rootstock, located near Bayaguana; DR3 = a Marsh grapefruit planting on Swingle citrumelo, P. trifoliata $\times C$. paradisi, rootstock, located near Hato Mayor; and DR4 = a Valencia sweet orange planting on sour orange rootstock, located near Hato Mayor. No aphid control procedures were applied in any of the plots. $T$. citricida was present in all locations when the experiments were started. For these plots, virus incidence was low to moderate (0 to 48\%) at the beginning of the study (17).

Sample collection. Due to the difference in virus temporal increase between the two pathosystems, the plots in category I (CTV incidence increased slowly) were sampled once per year in the spring, whereas the plots in category II (CTV incidence increased more rapidly) were sampled in the spring and fall of each year. Every tree was tested independently. Samples consisted of four leaf petioles from young, nearly fully expanded leaves taken from the periphery of each tree. For the Costa Rica and Dominican Republic plots, four petioles from each tree were placed in a number-coded paper envelope, and 20 individual envelopes corresponding to one row of trees were placed in sealable plastic bags to which was added approximately $50 \mathrm{~g}$ of a moisture-indicating silica gel (Tel-Tale, Grade 42; Grace Davison, Baltimore). The silica gel was changed as needed to insure that the specimens dried completely. The dry samples were then transported to the USDA-ARS laboratory in Orlando, FL. For the south Florida plots, fresh samples were transported to the U.S. Sugar Corporation research labs in Clewiston, FL, for immediate processing.

Enzyme-linked immunosorbent assay (ELISA) processing. The four leaf petioles of each sample were placed in $5 \mathrm{ml}$ of phosphate-buffered saline-Tween buffer and pulverized for $30 \mathrm{~s}$ in a Kleco tissue pulverizer (model 4200; Kinetic Laboratory Equipment Company, Visalia, CA). Extracts were assayed for presence of CTV via double-antibody sandwich indirect ELISA (18). Isolates of CTV were differentiated into two groups, designated here as $\mathrm{t}=$ total, i.e., all isolates, and $\mathrm{s}=$ severe, i.e., potentially declineinducing isolates (17). These designations were based on differential reactions to two monoclonal probes. The first probe consisted of a mixture of the monoclonal antibodies 11B1 and 3E10, which in combination act as a universal probe for all known isolates of CTV $(4,12$; S. M. Garnsey, unpublished data). The second probe consisted of the single monoclonal antibody MCA13, which reacts to the majority of decline-inducing and stem-pitting isolates of CTV but does not react to mild isolates found in Florida (23). Thus, a sample reacting to the universal probe was designated as total CTV, whereas a sample that reacted to both probes was designated as severe. Only the Costa Rica plots were found to have the severe isolates. Thus, for the Costa Rica plots, data were analyzed for total CTV content, i.e., both isolate groups combined, and for decline-inducing isolates only (e.g., CR1t = plot CR1 assayed for total CTV content versus CR1s = plot CR1 assayed for severe CTV content).

Description of model. Data for the CTV epidemics were analyzed using the spatiotemporal stochastic model for disease spread introduced by Gibson (13). In this model, members of a population are assumed to lie at the vertices of a square lattice with unit separation between rows and columns. At time $t$, a susceptible located at $x$ is assumed to acquire the disease probabilistically with a rate that is controlled by a parameter vector $a=$ $\left(a_{1}, a_{2}\right)$. Specifically, for that time period, $\mathrm{d} t$, the probability that 
$x$ becomes diseased in the time interval $(t, t+\mathrm{d} t)$ is equal to $r_{a}(x) \mathrm{d} t$, in which

$$
r_{a}(x)=\sum_{y \in D(t)}|y-x|^{-2 a_{2}}+a_{1}
$$

Here $D(t)$ is the set of sites (individuals) in the lattice that are infected at time $t, y$ is the location label for a site other than $x$, $y \in D(t)$ indicates that the summation is for all sites that have an infected tree at time $t$, and $|y-x|$ represents the distance from the susceptible at $x$. The parameter $a_{1}$ quantifies the rate at which a susceptible acquires the disease due to primary infection from sources outside the lattice, whereas $a_{2}$ quantifies the manner in which the infective challenge presented to a susceptible by a diseased individual in the population decreases with the distance between them. When $a_{1}$ is large or $a_{2}$ is small, the model produces disease maps that resemble random patterns. As $a_{2}$ increases, the secondary transmission occurs over shorter ranges and, so long as $a_{1}$ is not so large that primary infection dominates, disease maps generated by the model exhibit aggregation.

Given a temporal sequence of $k$ disease maps, $M_{1}, \ldots, M_{k}$, the model parameters can be estimated using the likelihood-based method previously described $(13,14)$. The reader is referred to these publications for a detailed discussion of this technique; only a summary is given here. The method involves calculating for each $i, i=$ $1, \ldots, k-1$, the relative values of a likelihood $L\left(M_{i} \rightarrow M_{i+1} \mid a\right)$ over a suitable range of parameter vectors $(a)$, in which $L\left(M_{i} \rightarrow M_{i+1} \mid a\right)$ represents the probability of observing $M_{i+1}$ as the set of diseased individuals, assuming that the disease progresses according to the above model with parameter vector $a$ and initial disease set $M_{i}$. As is the case here, when the observations consist of more than one transition, the likelihood for individual transitions can be multiplied together to give a likelihood for all transitions taken jointly, i.e.,

$$
L(a)=\prod_{i=1}^{k-1} L\left(M_{i} \rightarrow M_{i+1} \mid a\right)
$$

Computation of each likelihood $L\left(M_{i} \rightarrow M_{i+1} \mid a\right)$ is achieved using the MCMC algorithm developed by Gibson $(13,14)$. The parameter space used here is the same as previously described (13). Again, rather than work directly with the background parameter $a_{1}$, the transformed parameter $b=\left[\log \left(1+a_{1}\right)\right]^{1 / 2}$ is utilized and the model fitted to the data using a $21 \times 21$ set of values $\left(b, a_{2}\right)$ in which $b=0.0,0.123,0.25, \ldots, 2.5$ and $a_{2}=0.0,0.175,0.35, \ldots$, 3.5. The parameters determining the number of iterations and other aspects of the MCMC algorithm are also identical to those previously used (13).

\section{RESULTS}

Figures 1 and 2 show the relative variation of the likelihood $L(a)$, as estimated using the MCMC method, over the parameter vector for each of the observed epidemics. These are displayed as contour plots and are normalized so that the maximum value of $L(a)$ over the grid is unity. The results are discussed and interpreted for the two systems separately.

For category I situations in which the melon aphid was the predominant vector (i.e., plots g31-33, h31-33, and i31-33), there was a remarkable similarity in the likelihood surfaces (Fig. 1). With the exception of i33 (Fig. 2I), the larger values of $L(a)$ corresponded to cases in which $a_{2}$ lay toward the maximum of its tested range, and $b$ was small but nonzero, usually in the range $(0.25$, $1.0)$ (corresponding roughly to $a_{1}$ lying in the range $[0.07,1.75]$ ).

Inspection of $L(a)$ for category II situations in which the BCA is the main vector (CR1-4 and DR1-4) reveals a quite different story (Fig. 2). First, we remark that, in some cases, due to lack of progress of the epidemic over the observation period or too much infection prior to commencing observation, $L(a)$ revealed little regarding likely model parameters. In the case of CR2t, CR3t, CR4t,
DR2, and DR3, all that can be concluded from the analyses is that it is very unlikely that the observations arose as a result of purely local, short-range transmission (Fig. 2B to D, I, and J). In the case of CR1t, CR1s, CR3s, DR1, and DR4, the likelihood $L(a)$ was negligible, except over a region of parameter space in which $b$ was typically less than 1 and $a_{2}$ had values toward the lower end of its range. Importantly, the value of $L(a)$ was large for cases in which $b=0$ (Fig. 2A, E, G, H, and K).

Comparison of Figures 1 and 2 highlights the tendency for the evidence to favor a combination of background and nearest-neighbor transmission for the melon aphid systems and, predominantly, mid-range local interactions for systems involving the BCA. Note that there was not complete consistency within the two groups. The results for DR1 suggest a purely local interaction that operates over distinctly shorter ranges than for the other systems involving the BCA (Fig. 2H). Note also that when observations from a single plot were analyzed separately for severe and combined isolates the fact that the combined data 'include' the severe virus isolates intuitively lead us to expect a degree of consistency between the corresponding likelihood maps.

\section{DISCUSSION}

The spatiotemporal stochastic modeling resulted in strikingly different conclusions concerning CTV spread depending upon the CTV pathosystem investigated. For the A gossypii/CTV pathosystem (Florida) in which A. gossypii was the predominant vector species present and $T$. citricida was absent (category I plots), the estimated model parameter values support the hypothesis that the disease spreads through a combination of random background transmission (from inoculum sources outside the plots) and a local transmission that is primarily nearest-neighbor. In the case of the south Florida plots, a change was noted in CTV incidence as the canopies of individual trees within rows began to grow together. At this point, within-row transmission became apparent, resulting in aggregation among immediately adjacent trees (18). This was consistent with the interpretation of a nearest-neighbor transmission effect suggested by the stochastic model. Importantly, the likelihood surfaces strongly reject the hypothesis that the disease patterns were random, shown by the negligible $(\approx 0)$ values of $L(a)$ for large values of $b$ or for small values of $a_{2}$. Previous analyses of the $A$. gossypii/CTV pathosystem investigated in Spain were incapable of distinguishing the spatial patterns of CTV-infected trees from a random pattern (16). When the stochastic model was fitted to a portion of the Spanish data, the same conclusions were arrived at as for the A. gossypii/CTV data sets reported here for Florida. That is, CTV spread through a combination of random background transmission and a local interaction that operates over short distances (13). For the current study, the stochastic model parameters estimates also indicated that the patterns were highly unlikely to have arisen as a result of purely secondary transmission, because the $b$ values were clearly greater than 0 (Fig. 1) The only exception was for i33 (Fig. 1I), in which there was evidence in support of a transmission mechanism consisting of a combination of a random background process and a short-range local interaction that was significantly different from a nearest-neighbor interaction seen in the other data sets.

In contrast, when the model was applied to the $T$. citricida/CTV pathosystem for which $T$. citricida was the predominant vector but A. gossypii vectors were present as well (category II plots) (Fig. $2 \mathrm{~A}, \mathrm{E}, \mathrm{G}$, and $\mathrm{K}$ ), the results suggested a short-range local interaction that was not restricted to nearest-neighbor interactions. Results also suggested that the transmission may have been purely local (i.e., $a_{2}>0, b=0$ ) and that the presence of background infection (i.e., $b>0$ ) was not necessary to explain the observations. The results of the analysis were less conclusive in the case of CR2s (Fig. 2F). Here, $L(a)$ contours indicated that the observations were consistent with purely local (i.e., $a_{2}>0, b=0$ ) transmission (al- 
though operating beyond nearest-neighbor) and that a combination of random background and short-range local transmission $(b>0$, $a_{2}=3.5$ ) could not be discounted.

As discussed in recent studies, the two CTV pathosystems differ significantly due, in part, to the dispersal behavior of the predominant vector species (16-18). T. citricida is a citrus colonizer, whereas A. gossypii is a migrator from surrounding crops through citrus. Previous studies of the two pathosystems have led to the not unexpected conclusions that the diverse aphid vector biology induces differences in virus transmission and dispersal at the population level, which are reflected in sharp differences in the spatiotemporal dynamics of the virus. Stochastic modeling provides additional support for these conclusions but are subject to many other qualifications as well. Although one cannot use statistical inference tools based on asymptotic likelihood theory here (due to the lack of replicates and the nature of the likelihood surfaces), we can inter- pret the likelihoods as quantifying the relative degree of belief that we could ascribe to different parameter combinations on the basis of the observations alone.

The biology of the CTV pathosystem is extremely complex, and disease spread is affected by many processes operating at diverse scales. The most appropriate model for experimental observations should take into account the natural variability in observed patterns of spread and should represent the spatiotemporal nature of the process by capturing the interdependence between observations within the same experimental plot at different sampling times. We suggest that the simple stochastic models considered here are most suited to this task for several reasons. They allow key features of the process (here, background infection and local transmission) to be represented with few parameters. New developments in statistical computation mean that it is now possible to estimate parameters in these models within a sound statistical framework, thereby
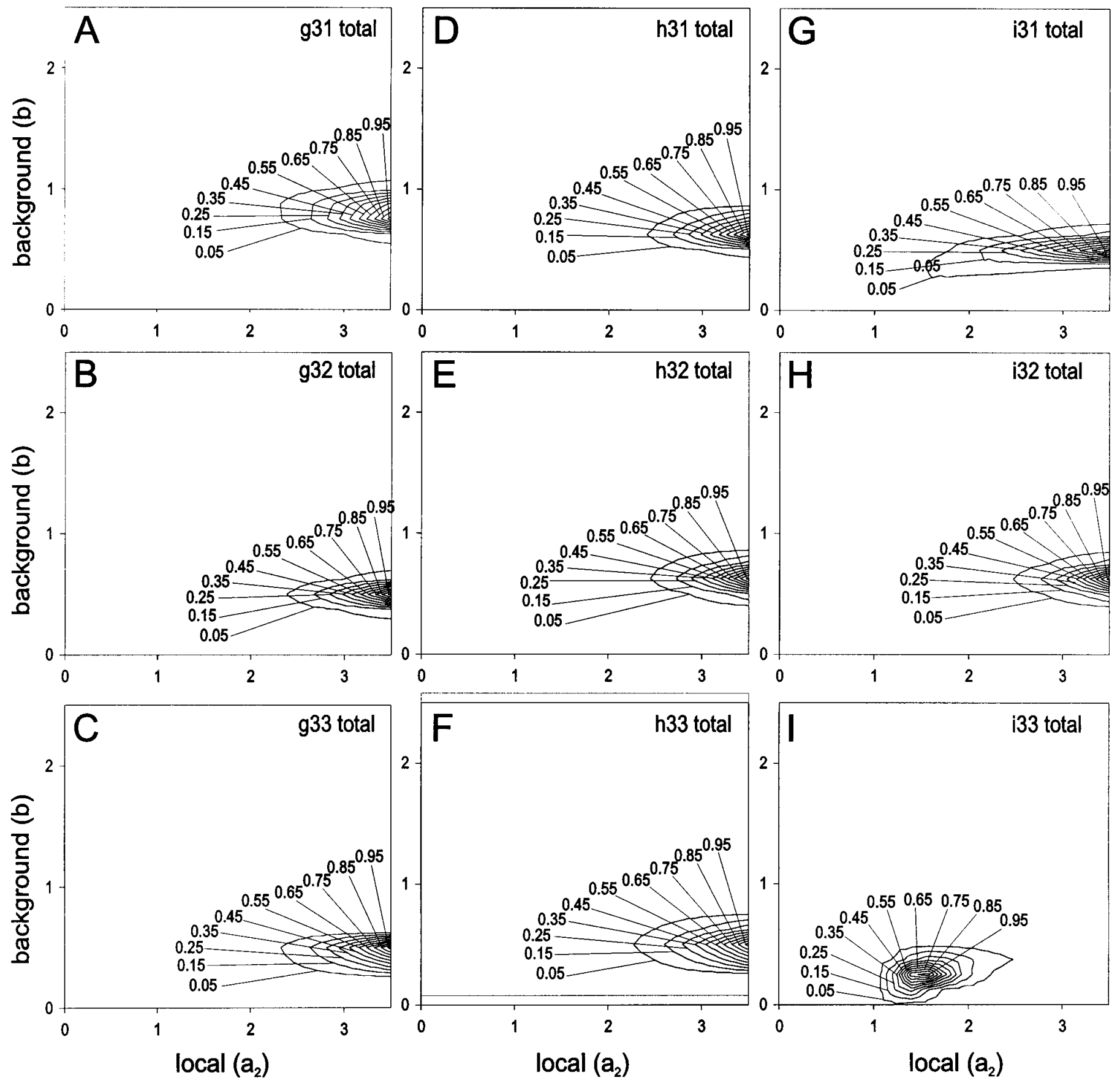

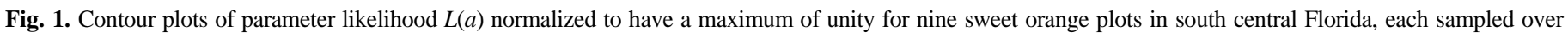
seven assessments. Plots were obtained by estimating the value of the likelihood over a $21 \times 21$ grid of parameter values with contours estimated by interpolation. 
'mapping' complex data sets to a simple parameter space characterizing the spread. Once fitted, models of this kind can be implemented and simulated easily to predict aspects of spread or to generate hypothetical epidemics, for example, in order to test the power of sampling protocols. In the case of the specific pathosystems investigated in this study, the methods clearly differentiated the spatiotemporal dynamics between the two pathosystems in a way consistent with the current understanding of CTV virus/aphid vector dynamics. Moreover, the simplicity of the models means that they are not restricted in application to the CTV system but can be extended to many other pathosystems for which analogous data are collected. Importantly, spatiotemporal modeling provides a flexible
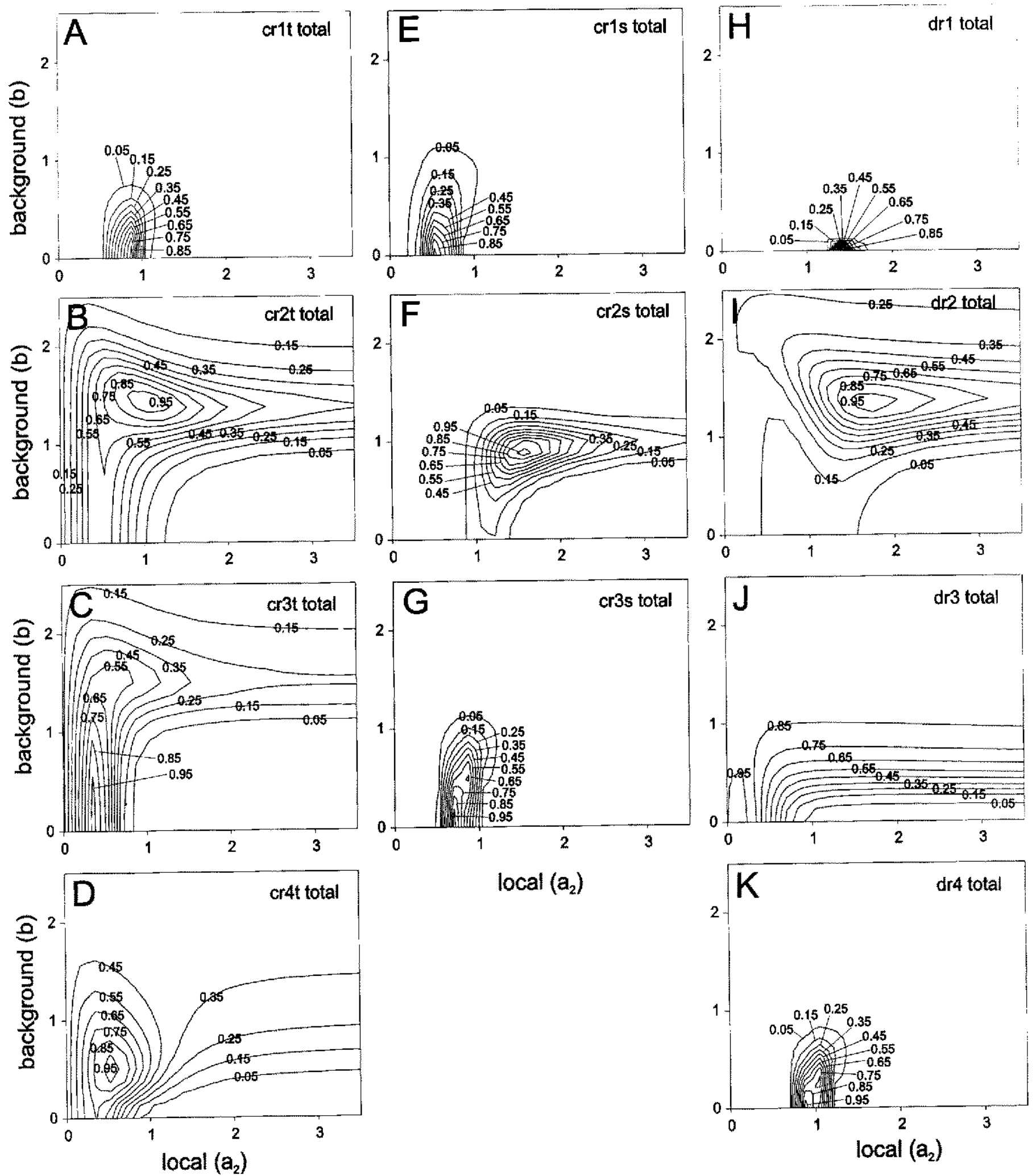

Fig. 2. Contour plots of parameter likelihood $L(a)$ normalized to have a maximum of unity for $\mathbf{A}$ to $\mathbf{G}$, plots in northeast Costa Rica, and $\mathbf{H}$ to $\mathbf{K}$, plots in east central Dominican Republic, each sampled over eight assessments. Plots were obtained by estimating the value of the likelihood over a $21 \times 21$ grid of parameter values with contours estimated by interpolation. 
framework that naturally takes into account how patterns evolve over time. In summary, we believe that the methods are an important addition to the tools for the analysis of complex data sets with the potential for widespread application and impact.

\section{ACKNOWLEDGMENTS}

Work by G. J. Gibson was supported by funds from the Scottish Office Agricultural, Environment, and Fisheries Department. We thank the management and technical staff at Guanaranja, S. A., Santa Cecelia, Guanacaste, Costa Rica; Consorcio Citricola del Este, C \& A., Hato Mayor, Republica Dominicana; Consorcio Citricos Dominicana, Villa Altagracia, Republica Dominicana; and Oscar de la Renta Citrus Plantations, Bayaguana, Republica Dominicana, for cooperation in this project and help collecting samples. We also thank J. Borbón for organization of all phases of effort in the Republica Dominicana and T. D. Riley, C. Bierman, and C. Halliday of the USDA, ARS, Orlando, FL, for technical assistance in processing samples, performing serological assays, and data processing.

\section{LITERATURE CITED}

1. Bar-Joseph, M., and Lee, R. F. 1989. Citrus Tristeza Virus. AAB Descriptions Plant Viruses No. 353.

2. Bar-Joseph, M., and Loebenstein, G. 1973. Effects of strain, source plant, and temperature on the transmissibility of citrus tristeza virus by the melon aphid. Phytopathology 63:716-720.

3. Bar-Joseph, M., Roccah, B., and Loebenstein, G. 1977. Evaluation of the main variables that affect citrus tristeza virus transmission by aphids. Proc. Int. Soc. Citricult. 3:958-961.

4. Cambra, M., Camarasa, E., Gorris, M. T., Garnsey, S. M., and Carbonell, E. 1991. Comparison of different immunosorbent assays for citrus tristeza virus (CTV) using CTV-specific monoclonal and polyclonal antibodies. Pages 38-45 in: Proc. Conf. Int. Organ. Citrus Virol., 11th. R. H. Brlansky, R. F. Lee, and L. W. Timmer, eds. IOCV, Riverside, CA.

5. Castle, W. S., Tucker, D. P. H., Krezdorn, A. H., and Youtsey, C. O. 1993. Rootstocks for Florida Citrus. 2nd ed. IFAS (Inst. Food Agric. Sci.), University of Florida, Gainesville.

6. Chellemi, D. O., Sonoda, R. M., Pelosi, R. R., and Cohen, M. 1991. Temporal and spatial comparisons between epidemics of citrus blight and citrus tristeza virus. Pages 289-296 in: Proc. Conf. Int. Organ. Citrus Virol., 11th. R. H. Brlansky, R. F. Lee, and L. W. Timmer, eds. IOCV, Riverside, CA.

7. Dickson, R. C., Flock, R. A., and Johnson, M. M. 1951. Insect transmission of citrus quick decline virus. J. Econ. Entomol. 44:172-176.

8. Dickson, R. C., Johnson, M. M., Flock, R. A., and Laird, Jr., E. F. 1956. Flying aphid populations in southern California citrus groves and their relation to the transmission of the tristeza virus. Phytopathology 46:204-210.

9. Fishman, S., Marcus, R., Talpaz, H., Bar-Joseph, M., Oren, Y., Salomon, R., and Zohar, M. 1983. Epidemiological and economic models for spread and control of citrus tristeza virus disease. Phytoparasitica 11:39-49.

10. Garnsey, S. M., Barrett, H. C., and Hutchison, D. J. 1987. Identification of citrus tristeza virus resistance in citrus relatives and its potential applications. Phytophylactica 19:187-191.

11. Garnsey, S. M., and Cambra, M. 1991. Enzyme-linked immunosorbent assay (ELISA) for citrus pathogens. Pages 193-216 in: Graft Transmissible Diseases of Citrus. C. N. Roistacher, ed. United Nations, Food and
Agriculture Organization, Rome.

12. Garnsey, S. M., Gottwald, T. R., and Borbón, J. C. 1996. Rapid dissemination of mild isolates of citrus tristeza virus following introduction of Toxoptera citricida in the Dominican Republic. Pages 92-102 in: Proc. Conf. Int. Organ. Citrus Virol., 13th. IOCV, Riverside, CA.

13. Gibson, G. J. 1997. Investigating mechanisms of spatiotemporal epidemic spread using stochastic models. Phytopathology 87:139-146.

14. Gibson, G. J. 1997. Markov chain Monte Carlo methods for fitting spatiotemporal epidemic stochastic models in plant pathology. Appl. Stat. 46:215-233.

15. Gibson, G. J., and Austin, E. J. 1996. Fitting and testing spatiotemporal stochastic models with applications in plant pathology. Plant Pathol. 45: 172-184.

16. Gottwald, T. R., Cambra, M., Moreno, P., Camarasa, E., and Piquer, J. 1996. Spatial and temporal analyses of citrus tristeza virus in eastern Spain. Phytopathology 86:45-55.

17. Gottwald, T. R., Garnsey, S. M., and Borbón, J. C. 1998. Increase and patterns of spread of citrus tristeza virus infections in Costa Rica and the Dominican Republic in the presence of the brown citrus aphid, Toxoptera citricida. Phytopathology 88:621-636.

18. Gottwald, T. R., Garnsey, S. M., Cambra, M., Moreno, P., Irey, M., and Borbón, J. C. 1997. Differential effects of Toxoptera citricida vs. Aphis gossypii on temporal and spatial patterns of spread of citrus tristeza. Pages 120-129 in: Proc. Conf. Int. Organ. Citrus Virol., 13th. IOCV, Riverside, CA.

19. Hermoso de Mendoza, A., Ballester-Olmos, J. F., and Piña Lorca, J. A. 1984. Transmission of citrus tristeza virus by aphids (Homoptera: Aphididae) in Spain. Pages 23-27 in: Proc. Conf. Int. Organ. Citrus Virol., 9th. S. M. Garnsey, L. W. Timmer, J. A. Dodds, eds. IOCV, Riverside, CA

20. Hughes, G., and Gottwald, T. R. 1998. Survey methods for citrus tristeza virus incidence. Phytopathology 88:715-723.

21. Marcus, R., Fishman, S., Talpaz, H., Salomon, R., and Bar-Joseph, M. 1984. On the spatial distribution of citrus tristeza virus disease. Phytoparasitica 12:45-52.

22. Moreno, P., Piquer, J., Piña, J. A., Juarez, J., and Cambra, M. 1988. Spread of citrus tristeza virus in a heavily infested citrus area in Spain. Pages 71-76 in: Proc. Conf. Int. Organ. Citrus Virol., 10th. L. W. Timmer, S. M. Garnsey, and L. Navarro, eds. IOCV, Riverside, CA.

23. Permar, T. A., Garnsey, S. M., Gumpf, D. J., and Lee, R. F. 1990. A monoclonal antibody that discriminates strains of citrus tristeza virus. Phytopathology 80:224-228.

24. Rocha-Peña, M. A., Lee, R. F., Lastra, R., Nibblet, C. L., Ochoa-Corona, F. M., Garnsey, S. M., and Yokomi, R. K. 1995. Citrus tristeza virus and its aphid vector Toxoptera citricida: Threats to citrus production in the Caribbean and Central and North America. Plant Dis. 79:437-445.

25. Schneider, H. 1954. Anatomy of bark of budunion, trunk, and roots of quick-decline-affected sweet orange trees on sour orange rootstock. Hilgardia 22:567-581.

26. Schwarz, R. E. 1965. Aphid-borne virus diseases of citrus and their vectors in South Africa. B. Flight activity of citrus aphids. S. Afr. J. Agric. Sci. 8:931-940.

27. Yokomi, R. K., Garnsey, S. M., Civerolo, E. L., and Gumpf, D. J. 1989. Transmission of exotic citrus tristeza virus isolates by a Florida colony of Aphis gossypii. Plant Dis. 73:552-556.

28. Yokomi, R. K., Lastra, R., Stoetzel, M. B., Damsteegt, V. D., Lee, R. F., Garnsey, S. M., Gottwald, T. R., Rocha-Peña, M. A., and Nibblet, C. L. 1994. Establishment of the brown citrus aphid (Homoptera: Aphididae) in Central America and the Caribbean Basin. J. Econ. Entomol. 88:1078-1085. 